\title{
Insights on the Working Principles of Secondary Electrospray Ionization High-Resolution Mass Spectrometry for Quantitative Analysis of Aerosol Chemical Composition
}

\author{
Xin Xu ${ }^{1,2,3} \cdot$ Jia Fa Zeng ${ }^{1,2,3} \cdot$ Dan Dan $\mathrm{Jin}^{1,2,3} \cdot$ Zheng Xu Huang ${ }^{1,2,3} \cdot{\text { Lei } \mathrm{Li}^{1,2,3} \cdot \text { Anthony S. Wexler }}^{4}$ Man Nin Chan ${ }^{5}$. \\ Zhen Zhou ${ }^{1,2,3} \cdot$ Yong Jie $\mathrm{Li}^{6} \cdot \mathrm{Xue} \mathrm{Li}^{1,2,3}$
}

Received: 29 September 2020 / Revised: 10 January 2021 / Accepted: 12 January 2021 / Published online: 16 February 2021

(c) The Author(s) 2021

\begin{abstract}
Real-time mass spectrometry (MS) has attracted increasing interest in environmental analysis due to its advantages in high time resolution, minimization of sampling artifact, and avoidance of time-consuming sample pretreatment. Among realtime MS methods, secondary electrospray ionization MS (SESI-MS) is showing great promise for the detection of organic compounds in atmospheric particulate matter. In this study, we demonstrated the working principles of secondary nanoelectrospray ionization (Sec-nESI) for real-time measurement of laboratory-generated organic aerosols using L-tartaric acid (TA) as a model compound. Factors affecting the detection of TA particles using a homemade Sec-nESI source coupled with a high-resolution mass spectrometer are systematically investigated. Temperature of ion transport capillary (ITC) was found to be the key factor in determining the ion signal intensity, which shows an increase of intensity by a factor of 100 from ITC temperature of $100-300{ }^{\circ} \mathrm{C}$ and could be attributed to more efficient desolvation and ionization. The characteristic fragment ion at $m / z 72.99$ was selected for quantitative analysis of TA at normalized collision energy of $50 \%$, the optimal value applied during MS/MS analysis. Detection limit of $0.14 \mu \mathrm{g} / \mathrm{m}^{3}$ and a linear range of $0.2-2.97 \mu \mathrm{g} / \mathrm{m}^{3}$ are achieved. Satisfactory correlations between ion signal intensity and particle surface area $\left(R^{2}=0.969\right)$ and mass concentration $\left(R^{2}=0.967\right)$ were obtained. Although an equally good correlation was observed between signal intensity and particle surface area, the good correlation between signal intensity and particle mass concentration indicates that high solubility of TA ensures efficient dissolution of TA in the primary ESI droplets for further ionization.
\end{abstract}

Keywords Particulate organic matter $\cdot$ Secondary nanoelectrospray ionization $\cdot$ High-resolution mass spectrometry $\cdot$ Normalized collision energy · Ion transport capillary

Xin Xu and Jia Fa Zeng contributed equally to the manuscript.

Yong Jie Li

yongjieli@umac.mo

$\triangle$ Xue Li

tamylee@jnu.edu.cn

1 Institute of Mass Spectrometry and Atmospheric Environment, Jinan University, Guangzhou, China

2 Atmospheric Pollution Online Source Analysis Engineering Research Center of Guangdong Province, Jinan University, Guangzhou 510632, China

3 Guangdong-Hongkong-Macau Joint Laboratory of Collaborative Innovation for Environmental Quality, Guangzhou, China
4 Air Quality Research Center and Departments of Mechanical and Aerospace Engineering, Civil and Environmental Engineering, and Land, Air and Water Resources, University of California, Davis, CA 95616, USA

5 Earth System Science Programme, The Chinese University of Hong Kong, Hong Kong, China

6 Department of Civil and Environmental Engineering, Faculty of Science and Technology, University of Macau, Taipa, Macau, China 


\section{Introduction}

Recent developments in real-time chemical characterization of aerosol particles have garnered attention for their high time resolutions (seconds to minutes) (Gallimore and Kalberer 2013; Li et al. 2015, 2017b; Brüggemann et al. 2015). Furthermore, compared to off-line methods, these real-time techniques can minimize artifacts due to condensation and evaporation, and avoid time-consuming sample pretreatment (Brüggemann et al. 2015). Advantages such as fast data acquisition and high sensitivity have made mass spectrometry (MS) among the most popular techniques for real-time aerosol chemical characterization (Pratt and Prather 2012; Li et al. 2015, 2017b). Aerosol mass spectrometers (AMS), which sample and analyze bulk aerosol particles, and, single-particle aerosol mass spectrometers (SPAMS), which sample and analyze individual particles, are the most widely used real-time mass spectrometric methods for aerosol analysis (Lee et al. 2013; Li et al. 2014, 2017b; Laskin et al. 2018; Passig et al. 2020). However, the extensive fragmentation of organic components by high-energy ionization confounds molecular identification in aerosol measurements despite the high sensitivity demonstrated by these instruments. Other widely used real-time techniques, such as online particle collection followed by ion chromatography (IC), are semi-continuous (typical time resolutions of tens of minutes). Moreover, IC-based methods are designed for water-soluble components (e.g., inorganic ions and very small carboxylic acids) and thus are not suitable for many hydrophobic organic compounds present in atmospheric particles (Li et al. 2017b).

Soft ionization MS, which does not cause extensive fragmentation, has proven to be a promising alternative for the molecular characterization of organic aerosols (Cooks et al. 2006; Huang et al. 2010; Gallimore and Kalberer 2013; Brüggemann et al. 2015). Several novel ionization techniques in recently developed ambient MS methods do not occur under high-vacuum conditions, which reduces potential artifacts caused by the evaporation of semi-volatile organics in particle phase. Hoffmann et al. (Hoffmann et al. 1998) studied particulate organics thermally vaporized within an atmospheric pressure chemical ionization (APCI) source and ionized by $\mathrm{O}_{2}{ }^{-}$ions produced via corona discharge. Direct analysis in real-time mass spectrometry (DART-MS) ionizes analytes using glow discharge plasma and has been successfully applied to the analysis of surface components on nanoparticles generated from a variety of atmospherically relevant organic compounds (Nah et al. 2013; Gross 2014).

In contrast to APCI and DART, secondary/extractive electrospray ionization technique generates primary reagent ions by applying conventional ESI (Gallimore and Kalberer 2013; Li et al. 2017a). Doezema et al. (2012) demonstrated that EESI-MS can detect both gaseous and particulate products from $\alpha$-pinene ozonolysis in real time. Later, Gallimore and Kalberer showed that EESI-MS can be used to measure tartaric acid (TA) particles with sizes of $70-200 \mathrm{~nm}$ and mass concentrations of $3-600 \mu \mathrm{g} / \mathrm{m}^{3}$ (Gallimore et al. 2017). Moreover, EESI-MS systems using a high-resolution mass spectrometer (mass resolution of 100,000 at $\mathrm{m} / \mathrm{z} 400$ ) have demonstrated unparalleled advantages over ESI-MS in chamber studies in both time resolution and quantification (Doezema et al. 2012; Gallimore et al. 2017). On the other hand, the ionization process is more complicated for the particles than for gases. For example, a recent study on the EESI mechanism revealed that surface energy and dissolution kinetics can influence the ionization process, and thus, that EESI might be more sensitive to particle surface layers than it is to the bulk particle composition (Kumbhani et al. 2018).

Despite the aforementioned progress, it remains necessary to lean the working principles of SESI and optimize relevant SESI-MS parameters to further improve the sensitivity, selectivity, and ease of use. In this study, a secondary nanoelectrospray ionization (Sec-nESI) source, which can achieve higher sensitivity with little solution consumption, was constructed and coupled with a high-resolution Quadrupole Orbitrap Mass Spectrometer (HRMS), then tested in measurements of particulate organics in real time. TA, a multi-functional dicarboxylic acid (Figure S1) found in atmospheric particles and believed to be formed secondarily from the photochemical oxidation of aliphatic and aromatic hydrocarbons, was used as a test compound (Röhrl and Lammel 2002; Claeys et al. 2004; Fu et al. 2014; Brent et al. 2014). Due to its low vapor pressure $\left(2.4 \times 10^{-12} \mathrm{mmHg}\right)$ and high hygroscopicity, TA tends to partition almost entirely to the particle phase (Hildemann and Saxena 1996; Röhrl and Lammel 2002; Treuel et al. 2007). Factors affecting the detection of TA particles using Sec-nESI-HRMS are systematically investigated and discussed below.

\section{Materials and Methods}

\subsection{Particle Generation and Characterization}

Particles were produced by nebulizing TA solutions of 3.3-667 $\mu \mathrm{mol} / \mathrm{L}$ with a commercial aerosol generator (Model 9302, TSI Inc., Shoreview, MN, US) in the laboratory (Fig. 1); the aerosol generator was operated under a constant flow of high-purity nitrogen gas $\left(\mathrm{N}_{2}, 99.999 \%\right)$, and the output flow rate was $2 \mathrm{~L} / \mathrm{min}$. TA (99\%, SigmaAldrich, St. Louis, MO) was used as received (Figure S1 and Table S1). A TA solution of $670 \mu \mathrm{mol} / \mathrm{L}$ was prepared 
Fig. 1 Schematic for the experimental detection of TA particles using an SMPS; the photo inset shows the relevant instrumentation in the laboratory

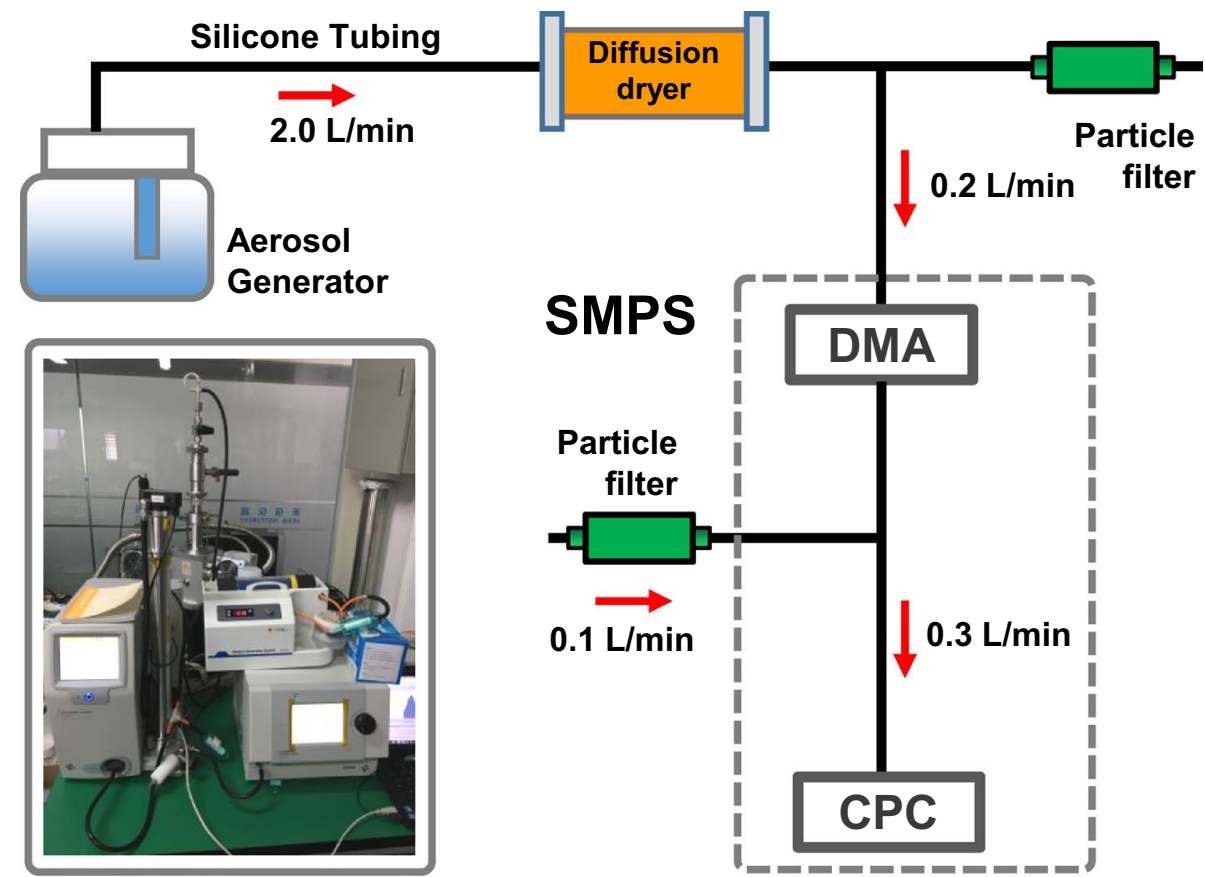

in ultrapure water (typically resistivity $18.2 \mathrm{M} \Omega \mathrm{cm}$ at $25{ }^{\circ} \mathrm{C}$ ), followed by stepwise dilution to lower concentrations. The TA solution concentrations and output flow rates were optimized in previous experiments to generate stable and reproducible particles (Figure S2).

The size distribution of the generated polydisperse particle population was characterized by a scanning mobility particle sizer (SMPS, Model 3938, TSI Inc., Shoreview, MN, US) (Figure S3). The sample and DMA sheath flow rates were set to 0.2 and $2 \mathrm{~L} / \mathrm{min}$, respectively (Fig. 1). Before entering the SMPS, particles were dried to $30 \%$ RH by passing through a diffusion dryer.

\subsection{The Sec-nESI-HRMS System}

A custom-built Sec-nESI source was developed using a commercially available nESI source (Nanospray Flex Ion Source, Thermo Fisher Scientific) (Fig. 2). Ultrapure water was used as the nESI solvent to generate the primary spray via a spray capillary with a flow rate of $200 \mathrm{~nL} / \mathrm{min}$ by a nano-pump (NCS-3500 nano-pump, Thermo Fisher Scientific). A sample stream containing particles was introduced directly into the stainless-steel Sec-nESI chamber through a Teflon tube ( $2 \mathrm{~mm}$ I.D.) at a constant flow rate. The geometry of the Sec-nESI chamber has been reported previously (Li et al. 2017a, 2018). MS analyses were performed with a Quadrupole Orbitrap Mass Spectrometer (Q Extractive, Thermo Fisher Scientific). Tandem MS measurements
Fig. 2 Schematic of TA particle experimental detection using Sec-nESI-HRMS; the inset photo shows the instrumentation depicted in the schematic

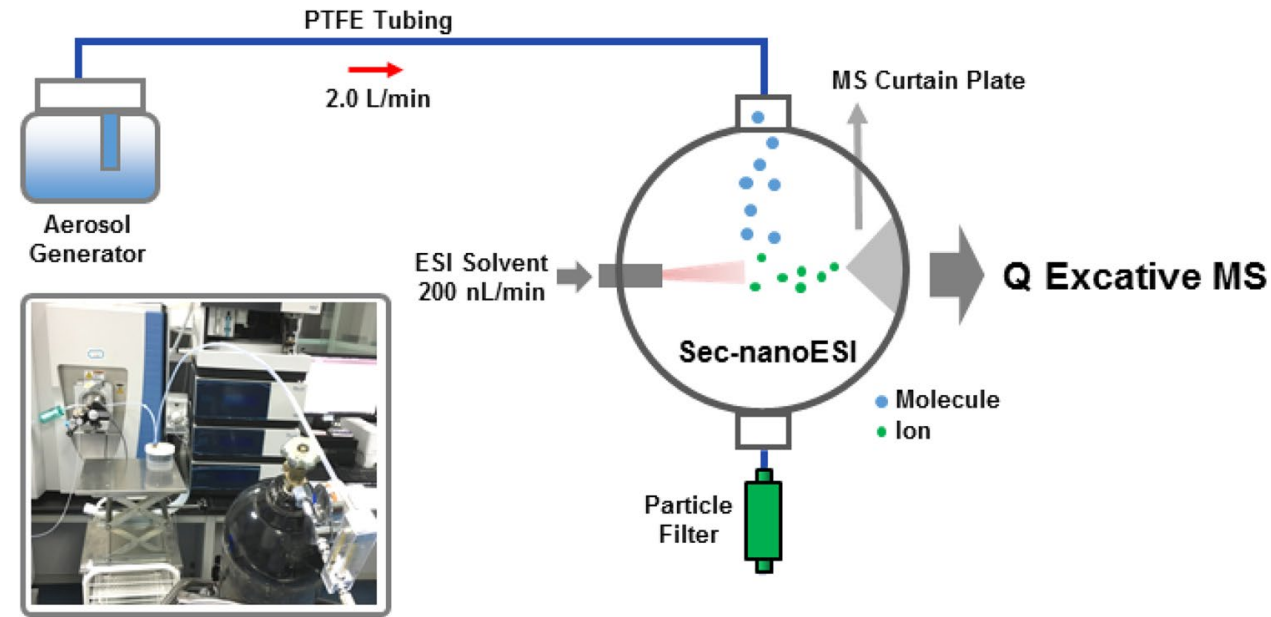


were performed using higher energy collisional dissociation (HCD), with high-purity $\mathrm{N}_{2}$ as the collision gas. Since deprotonated TA $\left([\mathrm{M}-\mathrm{H}]^{-}\right)$was observed in our preliminary test, $m / z 149.01$ was used as the precursor ion. MS and MS/ MS analyses were executed in negative ion mode at a resolution of 70,000.

\section{Results and Discussion}

\subsection{TA Particle Characterization by SMPS and Sec-nESI-HRMS}

Figure 3 shows the particle number-size distribution generated by nebulizing a TA solution of $67 \mu \mathrm{mol} / \mathrm{L}$. The particle size range spanned $20-150 \mathrm{~nm}$ with a mode diameter of $\sim 35 \mathrm{~nm}$ (Fig. 3a). The TA signal was seven times higher than the background under a particle sample flow rate of $2 \mathrm{~L} / \mathrm{min}$ into the Sec-nESI chamber (Fig. 3b). The signal intensity remained constant over a 1-min sampling period (Fig. 3b) and generally the values of standard deviation and coefficient of variance of replicate measurements are $140,480.2558-248,788.8165(n=3)$ and $0.1239-0.2294$ $(n=3)$, respectively. Similar results were achieved using particles from a $667 \mu \mathrm{mol} / \mathrm{L}$ TA solution (Figure S2d), for which good signal (at least one order of magnitude higher than the background) was observed even at lower sampling flow rates (e.g., $0.8 \mathrm{~L} / \mathrm{min}$; Figure $\mathrm{S} 2 \mathrm{~d}$ ); this may be attributed to the higher particle number and mass concentrations generated (Figure S3). In contrast, TA was hardly detected using $3.3 \mu \mathrm{mol} / \mathrm{L}$ TA solution for particle generation (Figure $\mathrm{S} 2 \mathrm{~b}$ ), as the number of particles in the chamber was not sufficient (Figure S3) to produce detectable amounts of TA ions. Thus, $67 \mu \mathrm{mol} / \mathrm{L}$ TA solutions were used in the following MS/MS investigations unless stated otherwise.

\subsection{Factors Affecting the Performance of Sec-nESI}

The Sec-nESI process involves production of primary ions and the delivery of aerosol particles (Fig. 2). Thus, factors including ESI voltage, ESI solution flow rate, and sample flow rate were investigated to optimize the Sec-nESI process. The ESI voltage, ESI solution flow rate, and sample flow rate parameters were initially set to the values typically used, i.e., $-2.5 \mathrm{kV}, 200 \mathrm{~nL} / \mathrm{min}$ and $2 \mathrm{~L} / \mathrm{min}$, respectively.

Figure 4a and Figure S4 show a significant increase in signal intensity with an increase in ESI voltage from - 2.0 to $-2.5 \mathrm{kV}$, indicating that satisfactory $\mathrm{nESI}$ process was achieved at $-2.5 \mathrm{kV}$ when ultrapure water was applied as the ESI solution. A higher ESI voltage might lead to more efficient formation of charged droplets and production of ionized molecules due to charge-transfer reactions, no matter which model of ESI process holds (Hermans et al. 2017). On the other hand, in the negative ion detection mode, nESI process becomes unstable and discharge may occur when ESI voltage is too high, for example explosion of droplets was observed at ESI voltage of $-2.7 \mathrm{kV}$ (Straub and Voyksner 1993). Thus, an ESI voltage of $-2.5 \mathrm{kV}$ was optimal in the range explored. A low ESI solution flow of $200 \mathrm{~nL} / \mathrm{min}$ was found to produce the highest signal among the flow rates studied (Fig. 4b and Figure S4), probably due to smaller droplet formation that is easier for solvent evaporation. Therefore, the ESI solution flow rate of $200 \mathrm{~nL} / \mathrm{min}$ was adopted as a sufficient ESI solution to generate primary ions. The use of ultrapure water can lead to higher ionization compared with the use of the mixtures of water and methanol (Martinez-Lozano Sinues et al. 2012; Lee and Zhu 2020).

The TA signal intensity increased with increasing sample flow rate. For example, the signal increased by a factor of seven when the sample flow rate was increased from 1.0 to $2.0 \mathrm{~L} / \mathrm{min}$ (Fig. $4 \mathrm{c}$ and Figure S2). This increase in TA signal can be explained by the fact that more particles were delivered into the chamber at higher sample flow rates. The sample flow rate was set to $2 \mathrm{~L} / \mathrm{min}$ to coordinate with the flow rate at the MS inlet interface $(1.8 \mathrm{~L} / \mathrm{min})$.

\subsection{Effects of ITC Temperature}

In our experiments, the TA signal intensity was significantly enhanced by increased ion transport capillary (ITC)
Fig. 3 a Particle number-size distribution and $\mathbf{b}$ extracted TA ion chromatogram (EIC) for particles generated by nebulizing a $67 \mu \mathrm{mol} / \mathrm{L}$ TA solution. The aerosol sample flow rate into the Sec-nESI chamber was $2 \mathrm{~L} / \mathrm{min}$. The smooth curve in b is obtained using Percentile Filter
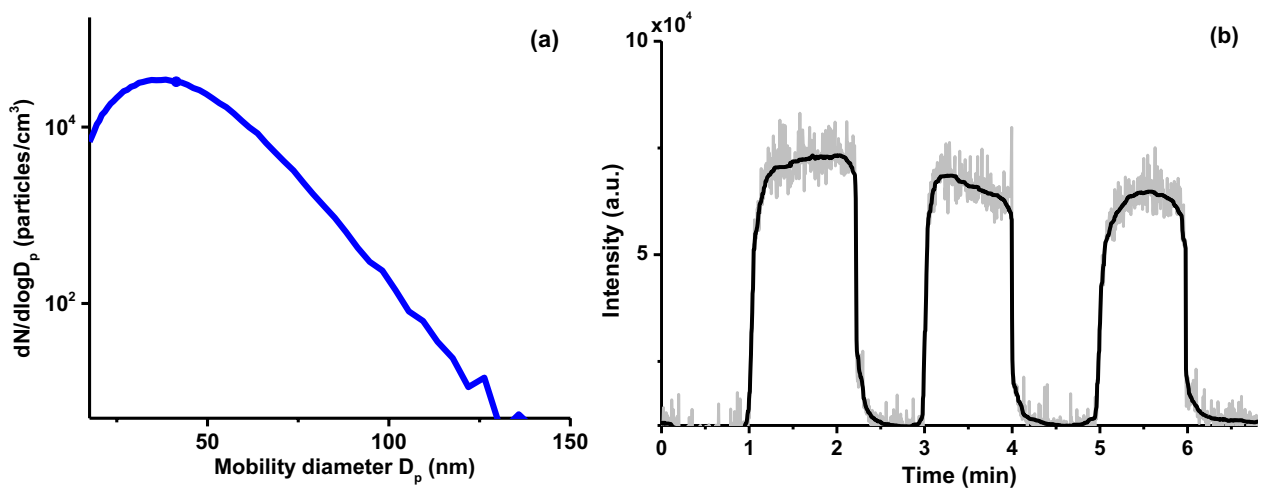

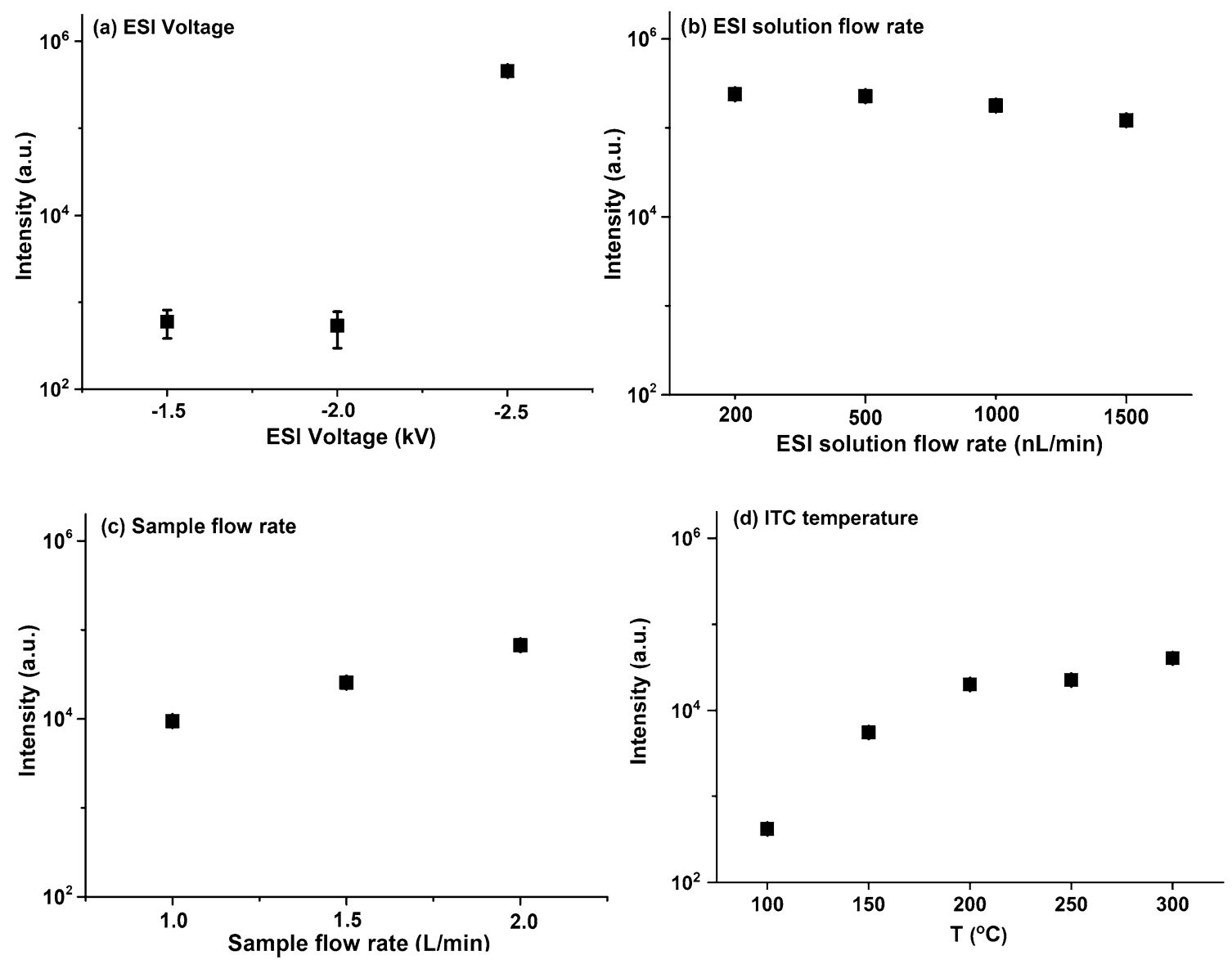

Fig. 4 Effects of changes in a ESI voltage, b ESI solution flow rate, c sample flow rate and d ITC temperature on measured signal intensity; note that a base-10 logarithmic scale is used for the $y$ axis. Mark-

temperature from 100 to $300{ }^{\circ} \mathrm{C}$ (Fig. 4 d and Figure S5), while the background noise was greatly reduced (Figure S5-S7), both of which contributed to higher signal-tonoise ratios. From a mechanistic perspective, a higher ITC temperature can enhance the evaporation and desolvation processes, thereby enhancing the ion-molecule reactions and increasing the delivery efficiency of ions into the mass analyzer for detection and, respectively (Zherebker et al. 2016; Martinez-Lozano Sinues et al. 2012). As a result, $300{ }^{\circ} \mathrm{C}$ was found to be the optimal value within the temperature range studied.

To further explore the influence of ITC temperature on TA detection, deprotonated TA at $\mathrm{m} / \mathrm{z} 149.01$ obtained at ITC temperatures of 300 and $150{ }^{\circ} \mathrm{C}$ was fragmented in the HCD cell at a normalized collision energy (NCE) of $35 \%$, the default NCE value of the instrument. The observed peaks at $\mathrm{m} / z$ 59.01 $\left(\mathrm{C}_{2} \mathrm{H}_{3} \mathrm{O}_{2}{ }^{-}\right), \mathrm{m} / \mathrm{z} 87.01\left(\mathrm{C}_{3} \mathrm{H}_{3} \mathrm{O}_{3}{ }^{-}\right), \mathrm{m} / \mathrm{z}$ $103.00\left(\mathrm{C}_{3} \mathrm{H}_{3} \mathrm{O}_{4}{ }^{-}\right)$, and $\mathrm{m} / z 131.00\left(\mathrm{C}_{4} \mathrm{H}_{3} \mathrm{O}_{5}{ }^{-}\right)$(Fig. 5 and Figure $\mathrm{S} 6$ ) are consistent with results from Gallimore and Kalberer, who used a LTQ Velos mass spectrometer (Gallimore and Kalberer 2013). The fragment ion at $\mathrm{m} / \mathrm{z}$

ers represent the average values and error bars represent the standard deviations of three replicate measurements

$72.99\left(\mathrm{C}_{2} \mathrm{HO}_{3}^{-}\right)$was reported by Brent et al., in which an ESI source and triple quadrupole mass analyzer were used (Fu et al. 2014). The peaks at $\mathrm{m} / z 59.98\left(\mathrm{CO}_{3}{ }^{-}\right), \mathrm{m} / z 61.99$ $\left(\mathrm{NO}_{3}{ }^{-}\right)$, and $\mathrm{m} / z 76.99\left(\mathrm{CHO}_{4}^{-}\right)$(Fig. 5 and Figure S6) are attributed to the ambient background. In the MS/MS spectrum obtained at $300{ }^{\circ} \mathrm{C}$ (Fig. 5 and Figure S7), background ions such as $\mathrm{m} / z 59.98\left(\mathrm{CO}_{3}{ }^{-}\right), \mathrm{m} / \mathrm{z} 61.99\left(\mathrm{NO}_{3}{ }^{-}\right)$and $\mathrm{m} / \mathrm{z}$ $76.99\left(\mathrm{CHO}_{4}^{-}\right)$are virtually nonexistent (Table S2). A TA fragmentation pathway is proposed in the supporting information based on the observed fragment ions (Figure S8).

\subsection{NCE Optimization for MS/MS Analysis}

Fragmentation efficiency can be optimized for a specific precursor ion by systematically varying the NCE. MS/MS analysis was performed at $300{ }^{\circ} \mathrm{C}$ for the deprotonated TA ion at $\mathrm{m} / z .149 .01$ under NCE values ranging from 10 to $70 \%$ (the default NCE value of the instrument is $35 \%$ ). Signal intensities were obtained and compared for fragment ion at $\mathrm{m} / \mathrm{z}$ 59.01, $\mathrm{m} / \mathrm{z}$ 72.99, $\mathrm{m} / \mathrm{z}$ 87.01, $\mathrm{m} / \mathrm{z} 103.00$, and $\mathrm{m} / \mathrm{z} 131.00$ (Fig. 6a). 
Fig. 5 MS/MS spectra of samples generated from a $67 \mu \mathrm{mol} / \mathrm{L}$ TA solution analyzed by a Sec-nESI-HRMS at $\mathrm{NCE}=35 \%$ and an ITC temperature of $300{ }^{\circ} \mathrm{C}$ (top) and $150{ }^{\circ} \mathrm{C}$ (bottom)
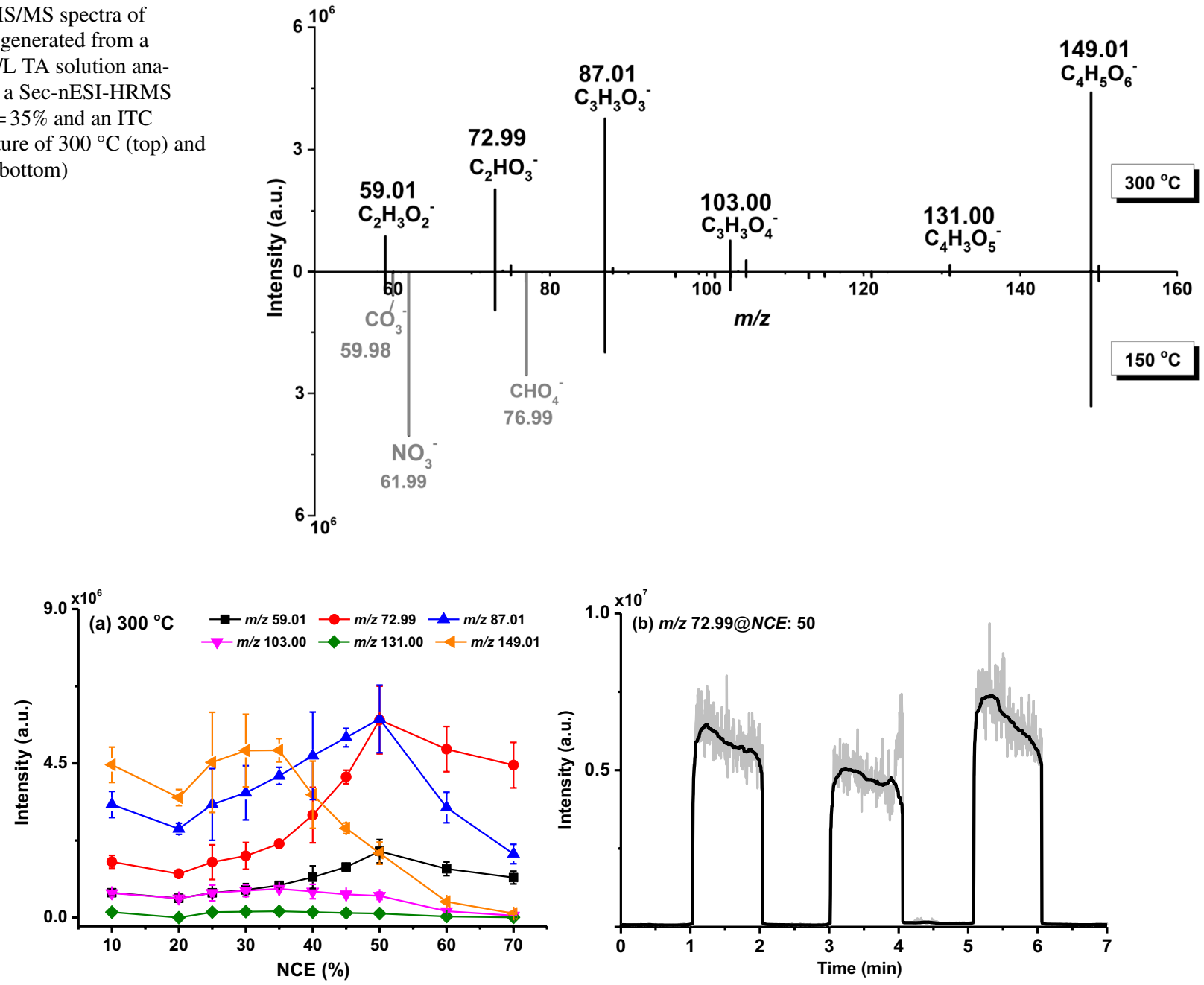

Fig. 6 At an ITC temperature of $300{ }^{\circ} \mathrm{C}$, a variations in the intensities of individual TA fragment ions (generated from a $67 \mu \mathrm{mol} / \mathrm{L}$ TA solution) under various NCE values, and $\mathbf{b}$ an EIC of $\mathrm{m} / \mathrm{z}, 72.99$ signal under an NCE of 50\%. Markers in Fig. 7a represent the average val-

ues and error bars represent the standard deviations of three replicate measurements. The smooth curve in Fig. $7 \mathrm{~b}$ is obtained using Percentile Filter

As shown in Fig. 6a, the TA ion intensity remained relatively constant when NCE was $\leq 35 \%$, and the resulting fragment ion mass spectra are similar to each other (i.e., the ion abundance decreases in the following order: $\mathrm{m} / \mathrm{z} 87.01, \mathrm{~m} / \mathrm{z}$ 72.99, $\mathrm{m} / \mathrm{z}$ 59.01, $\mathrm{m} / \mathrm{z}$ 103.00, and $\mathrm{m} / \mathrm{z}, 131.00$ ). The intensities of ions at $\mathrm{m} / \mathrm{z} 87.01$ and $\mathrm{m} / z 72.99$ increased with increasing NCE, suggesting that these two fragment ions may be formed more easily under higher NCE (Figure S8). At NCE values of $40-50 \%$, the intensity of the deprotonated TA ion dropped significantly, which may be ascribed to higher fragmentation efficiency. This assumption is supported by the significant increases in intensity for ions at $\mathrm{m} / \mathrm{z}$ 87.01 and $\mathrm{m} / z .72 .99$ and the slight intensity enhancement at $\mathrm{m} / \mathrm{z}$ 59.01. The highest intensity was achieved for fragment ions at both $\mathrm{m} / z 87.01$ and $\mathrm{m} / \mathrm{z} 72.99$ using an NCE of $50 \%$. The precursor ion and fragment ion intensities decreased at
NCE $\geq 60 \%$, which may be caused by the inability of the ions to remain in the HCD cell. Therefore, due to its sensitivity, specificity, and reproducibility, the fragment ion at $\mathrm{m} / \mathrm{z} 72.99$ was selected to investigate the detection limit and linear range for TA particle detection (Fig. 6b).

\subsection{Detection Limit and Linear Range}

Using the optimal parameters within the range explored, i.e., $-2.5 \mathrm{kV}$ ESI voltage, $200 \mathrm{~nL} / \mathrm{min}$ ESI solution flow rate, $2.0 \mathrm{~L} / \mathrm{min}$ sample flow rate, $300{ }^{\circ} \mathrm{C}$ ITC temperature, and 50\% NCE value for the ion at $\mathrm{m} / z$ 72.99, we investigated the detection limit and linear range using TA particles in the mass concentration range of $0-2.97 \mu \mathrm{g} /$ $\mathrm{m}^{3}$ (Figures S9 and S10). Figure 7a shows the relationship between the signal intensity at $m / z 72.99$ and the TA 

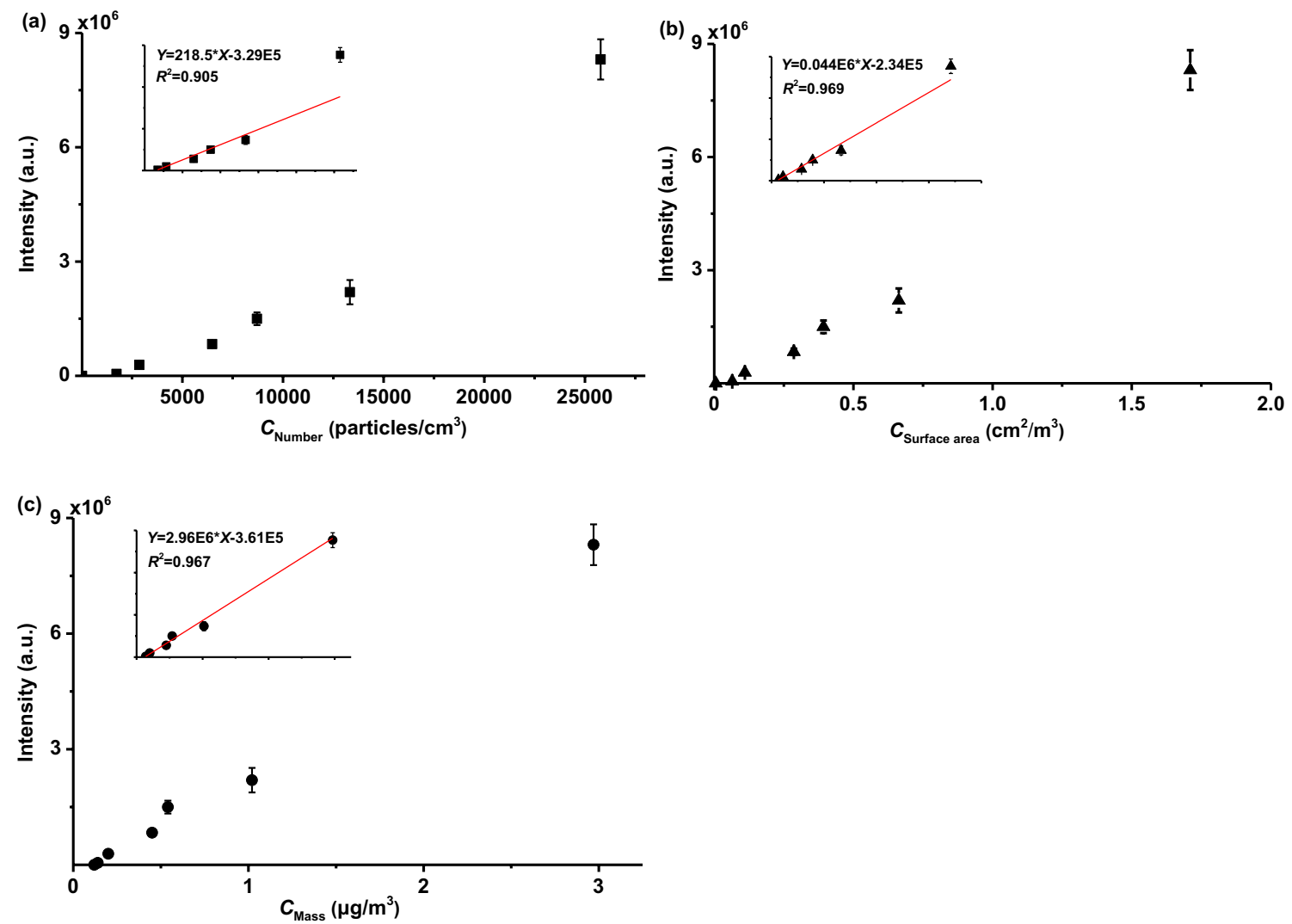

Fig. 7 Signal intensity of fragment ion at $\mathrm{m} / \mathrm{z} 72.99$ against a particle number concentration $\left(C_{\text {Number }}\right)$, b surface area concentration $\left(C_{\text {Surface area }}\right)$, and $\mathbf{c}$ mass concentration $\left(C_{\text {Mass }}\right)$ of aerosol samples generated from $0,3.3,6.7,13,33,67$, and $133 \mu \mathrm{mol} / \mathrm{L}$ TA solutions

particle number concentration measured by the SMPS. A non-linear relationship is observed $\left(R^{2}=0.905\right.$, Fig. 7a inset), which may arise from the fact that the mode diameter and the width (or deviation) of the log-normal distribution of the polydisperse particles for different concentrations might change, and thus the number concentration does not reflect the TA ionized. Figure $7 \mathrm{~b}$ shows the relationship between ion signal and TA particle surface area concentration, which is more linear $\left(R^{2}=0.969\right.$, inset of Fig. 7b) than the relationship between ion signal and number concentration; this suggests that the ionization process may have involved a surface process. Figure $7 \mathrm{c}$ shows the relationship between ion signal and TA particle mass concentration calculated from the SMPS size distribution by assuming particle sphericity and a TA density of $1790 \mathrm{~kg} /$ $\mathrm{m}^{3}$ (Table S1). In the $0.2-2.97 \mu \mathrm{g} / \mathrm{m}^{3}$ mass concentration range (Fig. 7c), the coefficient of determination $\left(R^{2}\right)$ is 0.967 (slope $=2.96 \times 10^{6}$, intercept $\left.=3.61 \times 10^{5}\right)$. Notably, the ion signal intensity correlates very well with both particle surface area $\left(R^{2}=0.969\right)$ and mass $\left(R^{2}=0.967\right)$ (Fig. 7b and Fig. 7c). Although an equally good correlation

under an ITC temperature of $300{ }^{\circ} \mathrm{C}$. Markers represent the average values and error bars represent the standard deviations of three replicate measurements

was observed between signal intensity and particle surface area, the good correlation between signal intensity and particle mass concentration indicates that high solubility of TA ensures efficient dissolution of TA in the primary ESI droplets for further ionization. As a result, the current technique has a great potential in quantifying the organics in the entire submicron particle even if the particle is not homogeneous, which is common in atmospheric particles.

Using pure water background signal measurements, a detection limit of $0.14 \mu \mathrm{g} / \mathrm{m}^{3}$ was estimated for TA particles. The LOD is calculated using a signal-to-noise ratio $(\mathrm{S} / \mathrm{N})$ of 3 according to $\mathrm{LOD}=3 \times \sigma_{\text {blank }} /$ sensitivity, where $\sigma_{\text {blank }}$ is the standard deviation of the background noise level measured at $0 \mathrm{ppb}$ of gas sample (i.e., pure $\mathrm{N}_{2}$ ). The detection limit obtained in this study is comparable to that reported previously $\left(0.22 \mu \mathrm{g} / \mathrm{m}^{3}\right)$ (Gallimore and Kalberer 2013). With analytical merits including high time resolution, high sensitivity, high selectivity, and low detection limit, this new method is well suited for the chemical characterization and quantification of laboratory-generated organic aerosols and chamber-derived SOA. 


\section{Conclusions}

We investigated the real-time measurement of laboratorygenerated TA particles using a custom-built Sec-nESI source coupled with a HRMS. Parameters involved in the Sec-nESI process, including ESI voltage, ESI solution flow rate, sample flow rate, and ITC temperature, were optimized. Using a specific fragment ion for qualitative and quantitative analysis and NCE for MS/MS analysis, TA can be quantified over a linear range of $0.2-2.97 \mu \mathrm{g} /$ $\mathrm{m}^{3}$ with high sensitivity (detection limit $=0.14 \mu \mathrm{g} / \mathrm{m}^{3}$ ). Among the parameters investigated, the ITC temperature had the most pronounced impact on ion signal intensity, which may be attributed to more efficient desolvation and ionization. In MS/MS measurements, different fragments showed quite different dependence on the applied NCE, implying that the NCE should also be tuned when exploring organic compounds with unknown structures. This work successfully demonstrates the highly sensitive detection of a multi-functional organic compound using sec-nESI-HRMS, demonstrating that secondary ionization using primary ions generated from either conventional ESI or nESI (as in this study) holds promise for the identification and quantification of organic particles in laboratory studies.

Supplementary Information The online version contains supplementary material available at https://doi.org/10.1007/s41810-021-00091-9.

Acknowledgements This work was supported by Local Innovative and Research Teams Project of Guangdong Pearl River Talents Program (2019BT02Z546), National Natural Science Foundation of China (no. 41675120), Science and Technology Program of Guangzhou (no. 706065441036), Science and Technology Project for International Cooperation of Guangdong Province (no. 2018A050506020) and Special Fund Project for Science and Technology Innovation Strategy of Guangdong Province (no. 2019B121205004).

Open Access This article is licensed under a Creative Commons Attribution 4.0 International License, which permits use, sharing, adaptation, distribution and reproduction in any medium or format, as long as you give appropriate credit to the original author(s) and the source, provide a link to the Creative Commons licence, and indicate if changes were made. The images or other third party material in this article are included in the article's Creative Commons licence, unless indicated otherwise in a credit line to the material. If material is not included in the article's Creative Commons licence and your intended use is not permitted by statutory regulation or exceeds the permitted use, you will need to obtain permission directly from the copyright holder. To view a copy of this licence, visit http://creativecommons.org/licenses/by/4.0/.

\section{References}

Brent L, Reiner J, Dickerson R, Sander L (2014) Method for characterization of low molecular weight organic acids in atmospheric aerosols using ion chromatography mass spectrometry. Anal Chem. https://doi.org/10.1021/ac403937e

Brüggemann M, Karu E, Stelzer T, Hoffmann T (2015) Real-time analysis of ambient organic aerosols using aerosol flowing atmospheric-pressure afterglow mass spectrometry (AeroFAPAMS). Environ Sci Technol. https://doi.org/10.1021/es506186c

Claeys M, Graham B, Vas G, Wang W, Vermeylen R, Pashynska V, Cafmeyer J, Guyon P, Andreae MO, Artaxo P, Maenhaut W (2004) Formation of Secondary Organic Aerosols Through Photooxidation of Isoprene. Science (80- ) 303(5661):1173-1176. https://doi.org/10.1126/science.1092805

Cooks RG, Ouyang Z, Takats Z, Wiseman JM (2006) Ambient mass spectrometry. Analyst 311(5767):1566-1570

Doezema LA, Longin T, Cody W, Perraud V, Dawson ML, Ezell MJ, Greaves J, Johnson KR, Finlayson-Pitts BJ (2012) Analysis of secondary organic aerosols in air using extractive electrospray ionization mass spectrometry (EESI-MS). RSC Adv 2(7):2930 2938. https://doi.org/10.1039/c2ra00961g

Fu PQ, Kawamura K, Cheng YF, Hatakeyama S, Takami A, Li H, Wang W (2014) Aircraft measurements of polar organic tracer compounds in tropospheric particles (PM 10) over central China. Atmos Chem Phys 14(8):4185-4199. https://doi. org/10.5194/acp-14-4185-2014

Gallimore PJ, Kalberer M (2013) Characterizing an extractive electrospray ionization (EESI) source for the online mass spectrometry analysis of organic aerosols. Environ Sci Technol 47(13):73247331. https://doi.org/10.1021/es305199h

Gallimore PJ, Giorio C, Mahon BM, Kalberer M (2017) Online molecular characterisation of organic aerosols in an atmospheric chamber using extractive electrospray ionisation mass spectrometry. Atmos Chem Phys 17(23):14485-14500. https://doi.org/10.5194/ acp-17-14485-2017

Gross JH (2014) Direct analysis in real time-a critical review on DARTMS. Anal Bioanal Chem 406(1):63-80. https://doi.org/10.1007/ s00216-013-7316-0

Hermans J, Ongay S, Markov V, Bischoff R (2017) Physicochemical parameters affecting the electrospray ionization efficiency of amino acids after acylation. Anal Chem 89(17):9159-9166

Hildemann LM, Saxena P (1996) Water-soluble organics in atmospheric particles: a critical review of the literature and application of thermodynamics to identify candidate compounds. J Atmos Chem 24(1):57

Hoffmann T, Bandur R, Marggraf U, Linscheid M (1998) Molecular composition of organic aerosols formed in the $\alpha$-pinene/ $\mathrm{O}_{3}$ reaction: implications for new particle formation processes. J Geophys Res Atmos 103(D19):25569-25578. https://doi. org/10.1029/98JD01816

Huang M-Z, Yuan C-H, Cheng S-C, Cho Y-T, Shiea J (2010) Ambient ionization mass spectrometry. Annu Rev Anal Chem 3(1):43-65. https://doi.org/10.1146/annurev.anchem.111808.073702

Kumbhani S, Longin T, Wingen LM, Kidd C, Perraud V, Finlayson-Pitts BJ (2018) New mechanism of extractive electrospray ionization mass spectrometry for heterogeneous solid particles. Anal Chem 90(3):2055-2062. https://doi.org/10.1021/acs.analc hem.7b04164

Laskin J, Laskin A, Nizkorodov SA (2018) Mass spectrometry analysis in atmospheric chemistry. Anal Chem 90(1):166-189. https://doi. org/10.1021/acs.analchem.7b04249

Lee JHJ, Zhu J (2020) Optimizing secondary electrospray ionization high-resolution mass spectrometry (SESI-HRMS) for the analysis of volatile fatty acids from gut microbiome. Metabolites 10(9):351

Lee BP, Li YJ, Yu JZ, Louie PKK, Chan CK (2013) Physical and chemical characterization of ambient aerosol by HR-ToF-AMS at a suburban site in Hong Kong during springtime 2011. J Geophys Res Atmos 118(15):8625-8639. https://doi.org/10.1002/jgrd.50658 
Li L, Li M, Huang Z, Gao W, Nian H, Fu Z, Gao J, Chai F, Zhou Z (2014) Ambient particle characterization by single particle aerosol mass spectrometry in an urban area of Beijing. Atmos Environ 94:323-331

Li X, Zhou Z, Huang Z, Gao W, Li M, Li L (2015) Techniques and instruments used for real-time analysis of atmospheric nanoscale molecular clusters: a review. Emerg Contam 1(1):33-38. https:// doi.org/10.1016/j.emcon.2015.05.001

Li X, Huang L, Zhu H, Zhou Z (2017a) Direct human breath analysis by secondary nano-electrospray ionization ultrahigh-resolution mass spectrometry: Importance of high mass resolution and mass accuracy. Rapid Commun Mass Spectrom 31(3):301-308. https:// doi.org/10.1002/rcm.7794

Li YJ, Sun Y, Zhang Q, Li X, Li M, Zhou Z, Chan CK (2017b) Realtime chemical characterization of atmospheric particulate matter in China: a review. Atmos Environ 158:270-304. https://doi. org/10.1016/j.atmosenv.2017.02.027

Li X, Huang DD, Du R, Zhang ZJ, Chan CK, Huang ZX, Zhou Z (2018) Real-time breath analysis by using secondary nanoelectrospray ionization coupled to high resolution mass spectrometry. J Vis Exp 2018(133):1-6. https://doi.org/10.3791/56465

Martinez-Lozano Sinues P, Criado E, Vidal G (2012) Mechanistic study on the ionization of trace gases by an electrospray plume. Int J Mass Spectrom 313:21-29. https://doi.org/10.1016/j. ijms.2011.12.010

Nah T, Chan M, Leone SR, Wilson KR (2013) Real time in situ chemical characterization of submicrometer organic particles using direct analysis in real time-mass spectrometry. Anal Chem 85(4):2087-2095. https://doi.org/10.1021/ac302560c

Passig J, Schade J, Rosewig EI, Irsig R, Zimmermann R (2020) Resonance-enhanced detection of metals in aerosols using singleparticle mass spectrometry. Atmos Chem Phys 20(12):7139-7152

Pratt KA, Prather KA (2012) Mass spectrometry of atmospheric aerosols - recent developments and applications. Part II: On-line mass spectrometry techniques. Mass Spectrom Rev 31(1):17-48. https ://doi.org/10.1002/mas.20330

Röhrl A, Lammel G (2002) Determination of malic acid and other C4 dicarboxylic acids in atmospheric aerosol samples. Chemosphere 46:1195-1199. https://doi.org/10.1016/S0045-6535(01)00243-0

Straub RF, Voyksner RD (1993) Negative ion formation in electrospray mass spectrometry. J Am Soc Mass Spectrom 4(7):578-587. https ://doi.org/10.1016/1044-0305(93)85019-T

Treuel L, Schulze S, Leisner T, Zellner R (2007) Deliquescence behaviour of single levitated ternary salt/carboxylic acid/water microdroplets. Faraday Discuss 137:265-278. https://doi.org/10.1039/ b702651j

Zherebker A, Kostyukevich Y, Kononikhin A, Roznyatovsky VA, Popov I, Grishin YK, Perminova IV, Nikolaev E (2016) High desolvation temperature facilitates the ESI-source H/D exchange at non-labile sites of hydroxybenzoic acids and aromatic amino acids. Analyst 141(8):2426-2434. https://doi.org/10.1039/c5an0 $2676 \mathrm{~h}$ 